\title{
FOUCAULT-BLANCHOT: LA SOLIDARIDAD DE LOS ANÓNIMOS
}

\author{
Carolina Villada Castro* \\ doi: 10.11144/Javeriana.uph37-75.fbsa
}

\begin{abstract}
RESUMEN
Este artículo analiza la figura del intelectual en Michel Foucault y Maurice Blanchot a partir de tres perspectivas: 1) la afirmación del anonimato del lenguaje; 2) la mirada crítica del poder y 3) la tarea ética del pensamiento y la escritura. Esto con el fin de caracterizar el intelectual como una voz anónima entre voces anónimas que interpelan el poder, un vigía en solidaridad con los anónimos y, finalmente, la responsabilidad de su escritura con los otros.
\end{abstract}

Palabras clave: filosofía; literatura; ética; solidaridad; anonimato

Universidad Nacional de Córdoba, Argentina.

Correo electrónico: carolina.villadacastro@gmail.com

Para citar este artículo: Villada Castro, C. (2019). Foucault-Blanchot: la solidaridad de los anónimos. Universitas Philosophica, 37(75), 175-202. ISSN 0120-5323, ISSN en línea 2346-2426. doi: 10.11144/Javeriana.uph37-75.fbsa 


\title{
FOUCAULT-BLANCHOT: SOLIDARITY OF THE ANONYMOUS
}

\begin{abstract}
This paper analyzes the figure of the intellectual in Michel Foucault and Maurice Blanchot, from three distinct perspectives: 1) The affirmation of the anonymity of language; 2) the critical approach against power; and 3 ) the ethics of thinking and writing. The intellectual is thus characterized as an anonymous voice among anonymous voices; as someone who holds power accountable; as a solidary guard for the anonymous-and his writing as the exercise of a specific kind of responsibility.
\end{abstract}

Keywords: philosophy; literature; ethics; solidarity; anonymity 


\section{Introducción}

ESTE TEXTO SE DEDICA A ANALIZAR la figura del intelectual desde las trayectorias paralelas de Michel Foucault y Maurice Blanchot, mutuos lectores e interlocutores, en cuyos textos se bosqueja una amistad en el pensamiento, pese a que no llegaron a entrar en contacto directo. Para este análisis se tratarán en cada intelectual tres puntos de encuentro desde los que sus pensamientos y prácticas se entrecruzaron: el primero consiste en su afirmación del anonimato del lenguaje, el segundo se refiere a sus relaciones críticas con el poder y el tercero alude a la tarea ética del pensamiento y de la escritura en que convergen sus trabajos. Con ello, se busca hacer explícita la manera en que ambos conciben el intelectual: primero, como un anónimo entre los anónimos; segundo, como un lugar desde donde el pensamiento interpela el poder; y tercero, como vigía solidario con los anónimos, que interpreta y asume la exigencia ética que conlleva su labor: en el caso de Foucault, el cuidado de sí y de los otros, y la práctica de la parresía; para Blanchot, la responsabilidad de la escritura con el otro.

Recientemente, la pregunta por la figura del intelectual en Foucault y Blanchot ha sido tratada por varios autores, entre los cuales destacamos particularmente a Quintana (2018), con su "Práctica del intelectual más allá del saber: Lyotard, Foucault, Blanchot", donde se reivindica el abandono de una figura clásica del intelectual de carácter prescriptivo, universalista o programático, en favor de un intelectual que se interpela e interpela el saber y sus prácticas, atento a los acontecimientos, e, incluso, un sujeto expuesto y alterado por las circunstancias, para quien "el saber ya no será salvaguarda, fundamento ni orientación" (Quintana, 2018, p. 425). Igualmente, subrayamos su bella tesis La exigencia de un habla plural. Literatura, pensamiento y comunidad en la obra de Maurice Blanchot (Quintana, 2014), concretamente su dilucidación de los intentos de Blanchot por pensar una comunidad literaria a partir de una relación de no apropiación con el otro en la escritura, que traza una nueva perspectiva para el pensamiento de la comunidad desde la filosofía y la literatura. Paralelamente, la tesis de Martínez (2011) Maurice Blanchot: La exigencia politica coincide en afirmar el abandono de la figura clásica del intelectual por Blanchot, su distanciamiento crítico del compromiso político y su apuesta, en cambio, por una ética del intelectual como vigía, e incluso como testigo, como una de las condiciones de posibilidad 
y necesidad de la literatura de la posguerra, configurando así la ficción como narrativa cuestionadora del poder. Por su parte, el artículo de Antonioli (2012) "Ecos de lo común" resalta en Blanchot la relación con el otro desde la extrañeza, la "extranjería" (p. 217) y la provisionalidad, que describe la dificultad en juego en el pensamiento contemporáneo de la comunidad y de "lo común".

Con todo, en este artículo nos dedicaremos a detallar el modo como en ambas figuras del intelectual hay una reivindicación singular del anonimato, que se suma al llamado tanto por una vida menos gobernada, como por un derecho a la insumisión que emerge y se defiende, ya desde la figura de esos anónimos con que se comparten las luchas locales, en el caso de Foucault, ya desde esas voces anónimas que se diseminan en el espacio narrativo, en el caso de Blanchot.

2. Foucault: el intelectual por una vida menos gobernada

La filosofia es el movimiento por el que, no sin esfuerzos y tanteos y sueños e ilusiones, nos desprendemos de lo que está adaptado como verdadero y buscamos otras reglas de juego. La filosofia no es sino el desplazamiento y la transformación de los marcos de pensamiento; la modificación de los valores recibidos y todo el trabajo que se hace para pensar de otra manera, para hacer algo otro, para llegar a ser otra cosa que lo que se es.

(Foucault, 1999c, p. 223)

LA ESCRITURA DE FoucaulT, ya se trate de sus libros, ensayos o entrevistas, tiene una multiplicidad de registros que continuamente se desplazan entre el rigor del archivista, el carácter incisivo del análisis filosófico, la ironía e indignación ante una práctica de poder o la necesidad y potencia de la imagen poética en el flujo de la escritura. Su lenguaje casi siempre es claro y contundente, y su público es tan amplio que, más allá de la academia, logra instigar e impulsar hasta la actualidad diferentes movilizaciones sociales y activismos. Como intentaremos mostrar en este texto, la fuerza de su pensamiento, aún en nuestros días, se debe a que supo prestar oídos a esa necesidad y deseo de una vida menos gobernada, propios de cualquier anónimo.

A continuación, nos dedicaremos, precisamente, a bosquejar el modo como esta pregunta ética por una vida más libre recorre su crítica a la modernidad, que aborda desde la problematización arqueológica de los discursos y del sujeto del 
discurso; su genealogía de las relaciones de poder desde una perspectiva micropolítica, en las antípodas de los análisis dialécticos y fenomenológicos; y, finalmente, su trabajo ético en torno a las prácticas de libertad o técnicas de sí.

En el trabajo arqueológico de Foucault, que incluye Las palabras y las cosas, La arqueología del saber e, incluso, El orden del discurso, la figura de un intelectual específico, en contravía del intelectual universal ${ }^{1}$, comienza a dibujarse a partir de la crítica a las políticas de la verdad que condicionan los discursos y los saberes locales, así como los forcejeos entre estos. En este sentido nos propone el análisis de los regímenes de enunciación, las condiciones de emergencia de los campos discursivos o la constitución de las disciplinas: "la disciplina es un principio de control de la producción del discurso. Ella le fija sus límites por el juego de una identidad que tiene la forma de una reactualización permanente de las reglas" (Foucault, 1992, p. 31).

A esto se suma la necesidad del estudio atento de las relaciones transdiscursivas y sus funciones de normalización, que están a la base de los procesos de institucionalización en la sociedad moderna. Considérense, por ejemplo, sus críticas a los pasajes transdiscursivos entre la pericia psiquiátrica y médica, que han servido durante décadas a los jueces y a la ortopedia social del Estado; o sus análisis de las imbricaciones entre los discursos de la biología, la emergencia de la economía liberal y las prácticas de biopoder del Estado moderno. Igualmente, nótese la necesidad de cuestionar la voluntad de verdad que impulsan los usos institucionales de los discursos:

El discurso verdadero, que la necesidad de su forma exime del deseo y libera del poder, no puede reconocer la voluntad de verdad que le atraviesa: y la voluntad, esa que se nos ha impuesto desde hace mucho tiempo, es de tal manera que la verdad que quiere no puede no enmascararla (Foucault, 1992, p. 20).

Justamente anota Blanchot (1986) sobre esta función de la arqueología, en tanto crítica de las condiciones de emergencia histórica de los discursos, o más

1 En contravía de toda consideración del intelectual como líder o guía, anota Foucault (1999b): "lo que los intelectuales descubrieron, tras la reciente avalancha, es que las masas no tienen necesidad de ellos para saber; saben claramente, perfectamente, lo saben mucho mejor que ellos; y lo dicen extraordinariamente bien" (p. 107). 
exactamente, de la historicidad de las racionalidades que los sostienen, sus funciones de verdad y poder:

Es así que desde La arqueología del saber donde parecemos complacernos con la ilusión de la autonomía del discurso (ilusión que nos encantaría en la literatura y en el arte quizá), se anuncian las relaciones múltiples del saber y del poder y la obligación de hacernos conscientes de los efectos políticos que produce en uno u otro momento la historia del antiguo deseo de dilucidar lo verdadero de lo falso (pp. 31-32)2.

No en vano, en El orden del discurso Foucault aproximará la arqueología a la genealogía como procedimientos insoslayables del intelectual específico que, desde su discurso local, indaga por los "órdenes" discursivos que limitan su campo de saber. Por consiguiente, la tarea de cada intelectual específico será "poner en duda nuestra voluntad de verdad; restituir al discurso su carácter de acontecimiento" (Foucault, 1992, p. 43).

Hasta aquí, la figura del intelectual específico a la que nos convoca Foucault indica la necesidad de problematizar los juegos de verdad y poder que pasan por los discursos que usamos, con base en los que actuamos e, incluso, desde los que a veces nos asumimos. En seguida, nos dedicaremos, precisamente, a tratar el anonimato del lenguaje, a fin de cuestionar el sujeto moderno a la base del discurso y, desde allí, a desenvolver el primer punto de encuentro que nos permite entretejer las figuras del intelectual en Foucault y Blanchot.

Desde la arqueología de los discursos, Foucault trata el anonimato del lenguaje, en un primer momento, a partir de su crítica del humanismo, esto es, del hombre como construcción discursiva e histórica del pensamiento clásico, que nos lleva inevitablemente al pasaje de las Las palabras y las cosas (Foucault, 1968):

Si esas disposiciones desaparecieran tal como aparecieron, si, por cualquier acontecimiento cuya posibilidad podemos cuando mucho presentir, pero

2 Las traducciones nuestras se acompañan en nota al pie con las citas respectivas en la lengua de partida en caso sean requeridas por el lector. Versión en francés: « C'est ainsi que dès L'archéologie du savoir où nous semblons nous complaire dans l'illusion de l'autonomie du discours (illusion dont s'enchanteraient la littérature et l'art peut-être), s'annoncent les rapports multiples du savoir et du pouvoir, et l'obligation de nous rendre conscients des effets politiques que produit à tel ou tel moment de l'histoire l'antique désir de démêler le vrai du faux. » 
cuya forma y promesa no conocemos por ahora, oscilaran, como lo hizo, a fines del siglo XvirI el suelo del pensamiento clásico, entonces podría apostarse a que el hombre se borraría, como en los límites del mar un rostro de arena (p. 375).

Posteriormente, el anonimato del lenguaje retorna a partir del abordaje del autor "no considerado, desde luego, como el individuo que habla y que ha pronunciado o escrito un texto, sino al autor como principio de agrupación del discurso, como unidad y origen de sus significaciones, como foco de su coherencia" (Foucault, 1992, p. 24). Por tanto, el autor no es más el sujeto que fundamenta el discurso, sino un componente del discurso mismo: "se trata de quitarle al sujeto (o a su sustituto) su papel de fundamento originario, y analizarlo como una función variable y compleja del discurso" (Foucault, 2005, p. 32). A esto se suma que cada discurso producirá sus sujetos, según cada campo de saber o disciplina. $\mathrm{Al}$ respecto, apunta Blanchot (1986):

el sujeto no desaparece; sino que se cuestiona su unidad demasiado determinada, ya que lo que suscita el interés y la indagación es su desaparición [...] o aún su dispersión que no lo elimina; sino que solo nos ofrece de él una pluralidad de posiciones y una discontinuidad de las funciones (p. 29)3.

En consecuencia, Foucault, en cuanto autor, se presentará en El orden del discurso (1992) como una voz entre voces anónimas, contingentes y provisionales en el murmullo incesante del lenguaje:

Me hubiera gustado darme cuenta de que en el momento de ponerme a hablar ya me precedía una voz sin nombre desde hacía mucho tiempo: me habría bastado entonces con encadenar, proseguir la frase, introducirme sin ser advertido en sus intersticios, como si ella me hubiera hecho señas quedándose, un momento, interrumpida. No habría habido por tanto inicio; y en lugar de ser aquel de quien procede el discurso, yo sería más bien una pequeña laguna en el azar de su desarrollo, el punto de su desaparición posible (p. 9).

3 « Le sujet ne disparaît pas, c'est son unité, trop déterminée, qui fait question, puisque ce qui suscite l'intérêt et la recherche, c'est sa disparition [...] ou encore sa dispersion qui ne l'anéantit pas, mais ne nous offre de lui qu'une pluralité de positions et une discontinuité de fonctions. » 
Paralelamente, en su conferencia “¿Qué es un autor?” (2005) Foucault puntualiza:

Todos los discursos, cualquiera que fuera su estatuto, su forma, su valor, y cualquiera que fuera el tratamiento al que se les somete, se desarrollarían en el anonimato de un murmullo. Ya no se escucharían las preguntas repetidas [ressassiées] durante largo tiempo: "¿Quién ha hablado realmente? ¿Seguro que es él y ningún otro? ¿Conqué autenticidad, o qué originalidad? ¿Y qué ha expresado de lo más profundo de sí mismo en su discurso?". Sino otras como estas: "¿Cuáles son los modos de existencia de este discurso? ¿Cómo se sostiene, cómo puede circular, quién puede apropiárselo? ¿Cuáles son los emplazamientos que en sí se disponen para unos sujetos posibles? ¿Quién puede cumplir estas diversas funciones de sujeto?". Y, detrás de todas estas preguntas, casi no se escucharía sino el ruido de una indiferencia: "¿Qué importa quién habla?" (pp. 32-34).

Esta afirmación del anonimato del lenguaje, que deriva de su trabajo arqueológico, posee una derivación ética que nos permite seguir perfilando la figura del intelectual, a quien corresponde la exigencia de escribir, pero no como un guía, al modo del intelectual universal, sino como un "anónimo entre anónimos". Es así como el intelectual específico permanece atento a las luchas locales y cotidianas de cualquier otro; escribe por la necesidad de problematizar y pensar de otro modo las funciones de poder de los saberes -no por el reconocimiento ni por la autoridad-; para "perder el rostro", como consecuentemente afirmaba Foucault en la introducción de La arqueología del saber (1979): “más de uno, como yo sin duda, escriben para perder el rostro. No me pregunten quién soy, ni me pidan que permanezca invariable: es una moral de estado civil la que rige nuestra documentación. Que nos deje en paz cuando se trata de escribir” (p. 29).

En suma, desde los trabajos arqueológicos de Foucault consideramos que la figura del intelectual específico se constata en su análisis crítico de los discursos locales y las políticas de verdad para indicar sus condiciones de emergencia histórica, provocar su discontinuidad o cuestionar las objetivaciones y sujeciones derivadas de tales discursos. A esto se añade la consideración del intelectual, en cuanto escritor, como voz anónima en el anonimato mismo del lenguaje, que permite bosquejar en Foucault una filosofía de la literatura como una de las 
expresiones más francas de ese ejercicio de remoción de nuestras propias sujeciones discursivas. No en vano, la literatura será no solo el espacio de las situaciones límite de la locura, la transgresión o el deseo, sino el resquicio por donde el anónimo murmura a la sombra del "rayo de luz del poder". En este sentido anota Morey (2014): "no sería descabellado entonces suponer que el proyecto de una arqueología del saber y el de una ontología de la literatura formaran el haz y el envés de una misma deriva reflexiva" (p. 249). Este asunto lo desarrollaremos más detalladamente en la segunda parte de este texto.

Por su parte, desde sus trabajos genealógicos, Foucault nos permite caracterizar al intelectual específico como vigía o velador dedicado a una analítica de las racionalidades, técnicas y economías de poder que han preponderado en la historia de la gubernamentalidad de Occidente (Castro, 2015). Pues, como apuntaba Foucault en Omnes et singulatim. Hacia una crítica de la "razón politica" (1990): "con el desarrollo de los Estados modernos y la organización política de la sociedad, el papel de la filosofía también ha sido el de vigilar los abusos del poder de la racionalidad política" (p. 96). Por tanto, el intelectual debe intentar problematizar con su mirada genealógica las técnicas de poder individualizadoras y totalizadoras allí donde las note en su campo de saber y sus prácticas.

$\mathrm{Al}$ respecto, sus aportes sobre las formas de gubernamentalidad son insoslayables: la proximidad entre las formas de gobierno del poder pastoral y el poder estatal en su curso Seguridad, territorio, población (2006) proporcionan la base de una singular analítica de las relaciones del poder, en contraste con los análisis marxistas, que mantiene la crítica de la razón de Estado, en tanto "gobierno cuya meta consiste en aumentar esta potencia en un marco extensivo y competitivo" (Foucault, 1990, p. 127). Además, complementa su análisis de la disciplina y ortopedia social con un análisis del biopoder a la base de la emergencia del Estado moderno. Con este movimiento, Foucault, en tanto intelectual diagnosticador (Adorno, 2010), llega al final de su curso Defender la sociedad (2000) a una aguzada crítica de las tecnologías de biopoder comunes al nazismo y socialismo, como dos excesos de poder cuyo rechazo le resulta inevitable a todo intelectual sobreviviente al siglo xx. De un lado, las prácticas racistas del nazismo, que lo conducen a una forma de "Estado suicida" (Foucault, 2000, p. 235); del otro, las prácticas racistas del socialismo en su lucha contra el 
enemigo y la eliminación del adversario: "cuando se trató, por consiguiente, de pensar el enfrentamiento físico con el adversario de clase en la sociedad capitalista, el racismo resurgió" (p. 236).

La actualidad de este análisis genealógico en perspectiva biopolítica se mantiene, al considerar la necesidad de la crítica de los intelectuales a las tecnologías de seguridad que persisten en los gobiernos neoliberales de hoy o, más exactamente, esa presunta "defensa de la sociedad", que no es más que la defensa de la existencia misma del Estado (Foucault, 2013, p. 205). Igualmente, su vigencia se debe a la necesidad del intelectual, como anónimo entre anónimos, de desviar los micropoderes y microfascismos cotidianos. De Spinoza a Foucault reverbera en la filosofía un aviso ineludible: el problema no solo es que el amo exista, sino que el esclavo desee su esclavitud; o, si se quiere, no es la revolución la que nos libera, sino las prácticas de libertad cotidianas. Al respecto, ilustra Foucault (1999b):

El poder no opera en un solo lugar, sino en lugares múltiples: la familia, la vida sexual, la forma en que se trata a los locos, la exclusión de los homosexuales, las relaciones entre hombres y mujeres... relaciones todas ellas políticas. No podemos cambiar la sociedad, a no ser que cambiemos estas relaciones. El ejemplo de la Unión Soviética es, desde este punto de vista, decisivo. Podemos decir que la Unión Soviética es un país en el que las relaciones de producción han cambiado a partir de la Revolución. El sistema legal con respecto a la propiedad ha cambiado también. Igualmente, las instituciones políticas se han transformado a partir de la Revolución. Pero las pequeñas relaciones de poder en la familia, la sexualidad, la oficina, entre los trabajadores, etc., siguen siendo iguales en la Unión Soviética a las de los demás países occidentales. Nada ha cambiado realmente (p. 278).

Paralelamente a esta labor genealógica, el intelectual específico, en tanto vigía, permanecerá atento a las luchas locales, antiautoritarias, minoritarias y cotidianas: "el objetivo principal de estas luchas es atacar no tanto 'tal o cual' institución de poder, o grupo, o élite, o clase, sino, ante todo, una técnica, una forma de poder" (Foucault, 1991, p. 60). El análisis genealógico no desemboca en una paranoia en torno al poder, sino más bien aguzando la mirada en torno al "agonismo" que se juega en cada forcejeo entre las estrategias de poder y las 
estrategias de resistencia: "una relación que es al mismo tiempo una incitación y lucha recíproca, es más bien una provocación permanente que una confrontación cara a cara que paraliza ambas partes" (Foucault, 1991, pp. 87-88). En este sentido, las nuevas resistencias y movilizaciones sociales se caracterizan por ser luchas transversales, cuyos objetivos son la resistencia a prácticas de individuación que socavan la vida en comunidad:

Son luchas que cuestionan el estatuto del individuo: por una parte, atacan el derecho a ser diferentes y subrayan todo aquello que hace verdaderamente individual al individuo. Por otra parte, atacan todo lo que separa al individuo, lo que rompe sus lazos con los otros, lo que rompe la vida de la comunidad, lo que lo obliga a respaldarse solo en él y lo ata a su propia identidad por una vía constringente (Foucault, 1991, p. 59).

En síntesis, los trabajos genealógicos de Foucault nos permiten caracterizar al intelectual como vigía o velador, que asume una labor crítica de la historicidad de las racionalidades de gobierno; por tanto, como apunta Adorno (2010), "se puede definir el trabajo de este tipo de intelectual ya no por su simple crítica al presente, sino por su empeño en demostrar la contingencia del presente, en desarticularlo como resultado de un proceso histórico" (p. 36). En contraste con el intelectual universal, el intelectual específico podrá colaborar en una formulación más precisa de los problemas, sin dejar de ser consecuente con un "principio de discreción" con el que su posición de intelectual se sitúa en horizontalidad con la de un ciudadano cualquiera (pp. 39-40). Simultáneamente, el intelectual, en tanto velador, es también el "testigo de una fuerza inédita" (Artières, 2010, p. 22). Así, en el agonismo de las estrategias, el intelectual se enfoca en esto que Artières indica como "lo por debajo de la historia, los movimientos de subjetivación individual y colectiva” (p. 23).

Ahora bien, estas trayectorias arqueológicas y genealógicas del pensamiento de Foucault, que permitieron esclarecer los modos de producción discursiva y las funciones de verdad sobre los sujetos, así como las formas de gobierno individualizadoras, se entretejen al final de su vida a partir de las preguntas por el cuidado de sí, en cuanto práctica de libertad, y por la parresía. Se despliega entonces un tránsito de la historia de los procesos de sujeción hacia la historia de los procesos de subjetivación. Al respecto, aclara Revel (2005b): 
La otra historia que Foucault intenta hacer, entonces, será en un primer momento una historia de las luchas y de las resistencias, después más directamente todavía, al final de los años de 1970, en el momento crucial que lo llevará a los temas de la estética de la existencia y de la ética, una historia de los modos de subjetivación (p. 213)

Esta estética de la existencia corresponde a la experimentación de otros modos de vivir posibles, estrategias para ser menos gobernados, en fin, modos de libertad en los que se juega precisamente el arte de vivir:

la "producción" propia de las relaciones de poder es, por tanto, una reacción a las limitaciones y a las resistencias que estas encuentran: es en esta medida que se puede decir que las relaciones de poder dependen de la resistencia, que se nutren de la libertad que paradójicamente las hace tambalear; aunque la producción de subjetividad es una reacción que posee el privilegio extraordinario de poder ser también -y siempre- una invención, un descubrimiento: una creación (Revel, 2005b, p. 209)5.

En el campo de tensiones, yuxtaposiciones, ajustes, desajustes y forcejeos entre las relaciones de poder y resistencias, la libertad se construye continuamente en el ejercicio cotidiano, local y anónimo de cualquiera por sustraerse a las objetivaciones discursivas, al gobierno de las conductas y a las normalizaciones que condicionan su diario vivir:

Todo el trabajo de Foucault consistirá precisamente en hacer de tal suerte que el movimiento de objetivación al que los individuos están necesariamente sometidos - para ser reconocidos como sujetos-, y los procesos de subjetivación que permiten a estos mismos sujetos devenir actores de su propia invención,

4 «L'autre histoire que Foucault cherche donc à faire, ce sera dans un premier temps une histoire des luttes et des résistances, puis plus directement encore, à la toute fin des années 1970, dans le grand tournant qui l'amènera au travail sur les thèmes de l'esthétique de l'existence et de l'éthique, une histoire des modes de subjectivation. »

5 «La "production" propre aux rapports de pouvoir est donc une réaction aux limitations et aux résistances que ceux-ci rencontrent: c'est dans cette mesure que l'on peut dire que les rapports de pouvoir dépendent de la résistance, qu'ils se nourrissent de la liberté qui paradoxalement les ébranle; alors que la production de subjectivité est une réaction qui possède le privilège extraordinaire de pouvoir être aussi - et toujours - une invention, une inauguration : une création. » 
dejen de presentarse como contradictorios; o, más exactamente, que, por una parte, la sujeción a una objetivación sufrida y, por otra parte, la resistencia a través de una subjetivación percibida como ruptura de esta objetivación, no sean simplemente identificadas como contradictorias; sino, al contrario, como íntimamente ligadas (Revel, 2005a, p. 174)

En la espesa trama de los micropoderes cotidianos, el intersticio es el lugar del cuidado singular de la libertad: "un ejercicio de uno sobre sí mismo, mediante el cual intenta elaborarse, transformarse y acceder a cierto modo de ser" (Foucault, 1999c, p. 394). En una relectura contemporánea de los antiguos, Foucault reivindica el cuidado de esta libertad como cuidado de sí, este ejercicio e interpelación cotidiana por cómo ser menos gobernado para afirmar más el deseo y la vida. Sobre esto anota Blanchot: "él se inclinó a buscar en los griegos no tanto una moral cívica, como una ética individual que le permitió hacer de su existencia - de lo que le quedaba por vivir- una obra de arte" (Blanchot, 1986, p. 63) ${ }^{7}$.

Este cuidado de sí, que consiste en cuidar nuestra libertad, exige, al mismo tiempo, cuidar de la libertad del otro; por tanto, la exigencia no solo radica en buscar ser menos gobernado, sino en no pretender gobernar a los otros ni querer conducir sus acciones; en desviar cualquier forma de dominación o sujeción: "el cuidado de sí es ético en sí mismo; pero implica relaciones complejas con los otros, en la medida en que este ethos de la libertad es también una manera de ocuparse de los otros" (Foucault, 1999c, p. 399). De este modo, el cuidado de sí se entrelaza posteriormente con la parresía:

6 «Tout le travail de Foucault consistera précisément à faire en sorte que le mouvement d'objectivation auquel les individus sont nécessairement soumis - pour être reconnus comme sujets - et les processus de subjectivation qui permettent à ces mêmes sujets de devenir acteurs de leur propre invention cessent de seprésenter comme contradictoires; ou plus exactement que l'assujettissement à une objectivation subie, d'une part, et la résistance à travers une subjectivation perçue comme rupture de cette objectivation, de l'autre, ne soient pas simplement identifiées comme contradictoires mais au contraire intimement liées. 》

$7 \quad$ «Ilfut enclin à rechercher chez les Grecs moins une morale civique qu'une éthique individuelle qui lui permit de faire de son existence - de ce qui lui restait à vivre - une ceuvre d'art. » 
se ve pues a través de estos textos surgir una noción de parresía, que podemos indicar con la idea de una palabra franca, del coraje de la verdad, en la encrucijada de una obligación de decir la verdad, de una problemática de la gubernamentalidad y de una relación consigo mismo: experiencia donde vienen a plegarse, a componerse las tres grandes dimensiones estudiadas por Foucault (Gros, 2003, p. 117) ${ }^{8}$.

La franqueza en el modo de vivir consiste no solo en una relación de honestidad consigo mismo o con la libertad que se cuida; sino, al mismo tiempo, en una relación de honestidad con el otro, es decir, con el cuidado de su libertad, en contraste con cualquier forma de egoísmo o utilitarismo. Esta es precisamente la "estilística" o "estética de la existencia" (Foucault, 2013, p. 230) a la que se dedicará Foucault al final de su vida.

Para finalizar, desde la perspectiva ética, la tarea del intelectual de Foucault consiste entonces en "mostrar a la gente que es mucho más libre de lo que piensa" (Foucault, 2013, p. 232). La filosofía se asume, por tanto, como una ascesis, no en el sentido cristiano de una renuncia de sí; sino como una relación consigo a partir de una práctica de libertad por la que continuamente nos abocamos a nuestras propias sujeciones, intentamos pensar de otro modo y transformar continua y singularmente nuestras conductas y modos de vivir. Como indica Francesco Paolo Adorno (2010): "para Foucault se trata de hacer de la ética, y no de la elaboración teórica misma, una piedra de toque de la práctica filosófica” (p. 47). Una vez más, en contraste con el intelectual universal o guía, el intelectual específico se caracteriza como un anónimo entre anónimos que intenta sustraer este anonimato de las objetivaciones discursivas y de las sujeciones de poder para afirmar, precisamente en este anonimato, el intersticio donde aún se inventa su libertad, donde puede ser "otros”, desconocido ante sí y entre otros, extraño y extranjero por las sendas del deseo vital.

8 «On voit donc à travers ces textes surgir cette notion de parrhèsia, que nous pouvons rendre par l'idée d'une parole franche, d'un courage de la vérité, au carrefour d'une obligation de dire vrai, d'une problématique de la gouvernementalité et d'un rapport à soi : expérience où viennent se plier, se composer les trois grandes dimensions étudiées par Foucault. » 
3. Blanchot: el intelectual por el derecho a la insumisión

Cada uno podía hablar con el otro, anónimo, impersonal, hombre entre hombres, acogido sin más justificación que ser otro hombre.

(Blanchot, 1986, pp. 9-10)

EN ESTA PARTE nos dedicaremos a la figura del intelectual a partir de tres aristas de los trabajos de Maurice Blanchot: el anonimato del lenguaje, la defensa del derecho a la insumisión y la responsabilidad del escritor. Desde la primera arista, el intelectual se podría caracterizar como una voz anónima entre voces anónimas, en cuyo anonimato se pone en juego - en términos de Foucault- una nueva política de enunciación. Desde allí podremos abordar la segunda arista, esto es, la afirmación de una escritura colectiva motivada por el rechazo al poder autoritario. Se tratará aquí la serie de manifiestos que Blanchot escribió con el Comité de Escritores y Estudiantes desde los años cincuenta para oponerse a de Gaulle, respaldar la deserción e insumisión a la Guerra de Argelia y apoyar las movilizaciones civiles en Mayo del 68. Justamente, esta trayectoria nos conducirá a la tercera arista, esto es, a la caracterización del intelectual como vigía y a la responsabilidad del escritor de transformar la narrativa en un espacio poético de hospitalidad con los ausentes o, si se quiere, de solidaridad con los anónimos.

Para comenzar, intentaremos establecer los vínculos entre el trabajo arqueológico de Foucault y sus aportes a la literatura, a los que se aproxima a Blanchot. Como vimos, la arqueología posibilita una afirmación del anonimato del lenguaje, que le permitirá a Foucault desenvolver su pensamiento sobre la literatura:

El tema del que quisiera partir podría formularse con unas palabras que tomo prestadas de Beckett: "Qué importa quién habla, alguien ha dicho qué importa quién habla”. En esta indiferencia pienso que hay que reconocer uno de los principios éticos fundamentales de la escritura contemporánea. Digo "ética" porque esta indiferencia no es exactamente un rasgo que caracterice la manera como se habla o se escribe; es más bien una especie de regla inmanente, retomada sin cesar, nunca enteramente aplicada, un principio que no marca a la escritura como resultado, sino que la domina como práctica [...]. En la escritura no hay manifestación o exaltación del gesto de escribir; no se trata 
de la sujeción [épinglage] de un sujeto en un lenguaje; se trata de la apertura de un espacio en el que el sujeto que escribe no deja de desaparecer (Foucault, 2005, pp. 7-8).

Esta ética de la escritura literaria no limita más el lenguaje al sujeto y desemboca en el "anonimato del murmullo" (Foucault, 2005, pp. 32-34), mientras se abandona el formalismo puro de los signos que retornan sobre sí. Se afirma entonces que el lenguaje literario "es el lenguaje alejándose lo más posible de sí mismo; y si este ponerse 'fuera de sí mismo', pone al descubierto su propio ser, esta claridad repentina revela una distancia más que un doblez, una dispersión” (Foucault, 1997, p. 13). Por tanto, esta experiencia del "afuera" del lenguaje literario en el que se dispersa y fragmenta continuamente es, paralelamente, la experiencia límite que pone fuera de sí a los escritores. Para Foucault esto se expresa en autores como Pseudo Dioniso Areopagita, Sade, Hölderlin, Nietzsche, Roussel, Mallarmé, Artaud, Bataille, Klossowski, entre otros. Es precisamente aquí donde se entretejen los pensamientos de Foucault y Blanchot y sus figuras del intelectual: para ambos, pensar, escribir o ficcionar corresponden a experiencias que interpelan, desbordan los límites del poder del sujeto, remueven sus mismas sujeciones discursivas y, al contrario, abocan a las experiencias límite del deseo, la transgresión, la locura, la muerte o, simplemente, el contacto con lo desconocido ante sí o en sí. Allí es donde la escritura literaria exige "dejar que las cosas sean" o "dejar que hombres se encuentren" (Foucault, 1997, p. 19) sin condicionarlos por los juegos de saber, poder o verdad. En el lenguaje literario, el hombre no impone más su ley o su voluntad de verdad; sino que él mismo es reconducido por el lenguaje como uno de sus simulacros o espectros:

Como si, en esta retirada, en este hueco que quizás no sea más que la irresistible erosión de la persona que habla, se liberara el espacio de un lenguaje neutro; entre el narrador y ese compañero indisociable que no le acompaña, a lo largo de esa delgada línea que los separa como separa también el Yo que habla del Él que él es en su ser hablado, se precipita todo el relato, desplegando un lugar sin lugar que es el afuera de toda palabra y de toda escritura, y que las hace aparecer, las desposee, les impone su ley, y manifiesta en su desarrollo infinito su reverberación de un instante, su fulgurante desaparición (Foucault, 1997, pp. 72-73). 
Este es precisamente el umbral de la escritura en la literatura moderna: el deslizamiento del "yo" al "él" (Blanchot, 2002, p. 29), la emergencia de esa voz anónima que ya no da cuenta de grandes relatos, sino que yerra entre otras voces anónimas, de fragmento en fragmento, donde recomienza y "se repite con una dispersión infinita” (Blanchot, 2002, p. 29). En esta literatura se pone en juego la crítica y la posibilidad de la literatura misma en medio de ese "murmullo interminable formado por el conjunto histórico de todo lo que efectivamente se ha dicho" (Morey, 2014, p. 254). Con todo, este anonimato del lenguaje provoca, en términos de Foucault, una nueva política enunciativa. Se trata de la proliferación de las voces anónimas, dado que el narrador en tercera persona es apenas un punto de múltiples combinaciones y variaciones entre ellas?.

Emerge entonces, según Blanchot (2008a), un "habla plural" que no solo describe las sendas de la literatura moderna y contemporánea, sino que a partir de los años cincuenta se consolida en una escritura colectiva y anónima en las que participa en medio de las protestas de la época ${ }^{10}$. Es así como, desde esta primera arista, podemos caracterizar al intelectual como una voz anónima entre voces anónimas que se expone al lenguaje para remover sus sujeciones y objetivaciones

9 Tal como mostró Benveniste en Problemas de lingüistica general I (1997), cuando analiza "la naturaleza de los pronombres" ((Benveniste, 1997, pp. 172-178)

10 Es necesario aclarar aquí que este trabajo no se dedicará a prolongar la polémica ni a realizar juicios sobre las posturas derechistas del joven Blanchot de los años 30 y su participación en periódicos nacionalistas. De un lado, porque preponderamos la autonomía de los textos sobre la personalidad de sus autores en una tentativa de evitar análisis psicologistas. De otro lado, con Foucault, consideramos como foco de interés la transformación de Blanchot como intelectual, debida a los acontecimientos que modificaron e interpelaron posteriormente su vida y pensamiento. En este sentido, destacamos que sus años de retiro y silencio político de 1938-1953 no limitaron el desenvolvimiento de su pensamiento crítico: "ninguna duda de que la interrupción del compromiso político no solo favoreció la escritura ficcional, sino igualmente el pensamiento crítico" [ « nul doute que l'interruption de l'engagement politique a non seulement favorisé l'écriture fictive, mais également la pensée critique. »] (Hoppenot, 2008, p. 7). No en vano, en 1947 en Après coup comienzan sus escritos sobre Auschwitz y su tematización sobre el ocaso de los relatos, más aún, en El espacio literario -como indica Agamben en el documental Maurice Blanchot de Hugo Santiago 1998- se dedicará a la pregunta sobre la posibilidad de la literatura tras Auschwitz. Así mismo, preponderamos su amistad con Lévinas, Bataille, Antelme, Duras, Mascolo, entre otros, con quienes se acercó a los movimientos de resistencia y a la izquierda. Incluso tras su retiro al final de su vida, Blanchot va a mantener una escritura que no cesa de "velar" o, si se quiere, de estar atenta al rechazo de cualquier forma de autoritarismo, racismo o despotismo, tal como intentaremos mostrar en el curso de este texto. 
discursivas, afirmarse como un pliegue más del discurso y, no obstante, en cuanto voz entre voces, acoger a los anónimos en una suerte de comunidad literaria.

Sobre esto Bordeleau (2012) aclara: "es respecto de la literatura, y en diálogo con Blanchot, que Foucault ha desarrollado su concepción de un afuera a ras del lenguaje que permite desprenderse de la forma de la interioridad privada y que culmina en una politización inédita de la apuesta enunciativa” (pp. 65-66 ${ }^{11}$. En este sentido, a partir de los años cincuenta Blanchot se dedicó a la escritura de varios manifiestos junto al Comité de Estudiantes y Escritores que se opusieron al autoritarismo y militarismo promovido por de Gaulle, apoyando la deserción de los civiles en la Guerra de Argelia y la serie de movilizaciones sociales durante Mayo del 68. Al respecto anota Hoppenot (2008): "este movimiento de juventud, mantenido por numerosos intelectuales y escritores a los que se siente próximo, libera un habla común, comunitaria, anónima, de la que recordará muchas veces, tras los acontecimientos, la exigencia, la gravedad y la necesidad" (p. 10 ${ }^{12}$.

Estos manifiestos afirmaban un rechazo común a la privación de los derechos cívicos sin pretensiones de proponer programas o promesas políticas. Al contrario, la potencia de esta escritura colectiva estuvo tanto en la fuerza del rechazo de una comunidad de anónimos a cualquier forma de reducción del poder político al militarismo y al racismo, como en la exigencia de solidaridad con los ausentes o con aquellos que no podían hablar. En "Le refus" -texto que apareció en la revista 14 Juillet junto con los de otros intelectuales como Antelme, Nadeau, Morin, entre otros- Blanchot caracteriza este rechazo categórico, esta afirmación común de un "no":

Los hombres que rechazan y que están vinculados por la fuerza del rechazo, saben que aún no están juntos. El tiempo de la afirmación común les ha sido retirado. Lo que les queda es lo irreducible del rechazo, la amistad de

11 «C'est en référence à la littérature, et en dialogue avec Blanchot, que Foucault a développé sa conception d'un dehors à même le langage qui permet de se déprendre de la forme de l'intériorité privée, et qui culmine dans une politisation inédite de l'enjeu énonciatif. » (Bordeleau, 2012, pp. 65-66).

12 « Ce mouvement de jeunesse, soutenu par de nombreux intellectuels et écrivains dont il se sent proche, libère une parole commune, communautaire, anonyme dont il rappellera maintes fois, bien après les événements, l'exigence, la gravité et la nécessité. » 
este "No" cierto, inamovible, riguroso, que los mantiene unidos y solidarios" (Blanchot, 2008b, p. 28) ${ }^{13}$.

Para retomar los términos de Foucault, lo que está en juego no es una táctica individualista o, si se quiere, el interés de un individuo, sino esta fuerza anónima por una vida en común:

Cuando rechazamos, rechazamos por un movimiento sin indiferencia, sin exaltación y anónimo, tanto como se puede, pues el poder de rechazar no se cumple a partir de nosotros mismos, ni solo en nuestro nombre, sino a partir de un comienzo muy limitado que pertenece, en primer lugar, a los que no pueden hablar (Blanchot, 2008b, p. 29) ${ }^{14}$.

Posteriormente, Blanchot participó en la escritura y firma del Manifiesto de los 121: Declaración sobre el derecho a la insumisión en la guerra de Argelia donde se denunciaron los encarcelamientos de civiles por desertar de la guerra o por aliarse a los argelinos, y se afirmó la resistencia a los poderes públicos que torturaban y mantenían la guerra colonial, imperialista y racista contra Argelia. La crítica fue contundente:

Ni guerra de conquista, ni guerra de "defensa nacional", la guerra de Argelia se convirtió prácticamente en una acción propia del ejército y de una casta que evitan ceder ante un levantamiento al que incluso el poder civil, dándose cuenta de la caída general de los imperios coloniales, parece dispuesto a darle sentido (Manifiesto de los 121, citado en Blanchot, 2008b, p. 51) ${ }^{15}$.

13 «Les hommes qui refusent et qui sont liés par la force du refus, savent qu'ils ne sont pas encore ensemble. Le temps de l'affirmation commune leur a précisément été enlevé. Ce qui leur reste, c'est l'irréductible refus, l'amitié de ce Non certain, inébranlable, rigoureux, qui les tient unis et solidaires. »

14 «Quand nous refusons, nous refusons par un mouvement sans mépris, sans exaltation, et anonyme, autant qu'il se peut, car le pouvoir de refuser ne s'accomplit pas à partir de nous-mêmes, ni en notre seul nom, mais à partir d'un commencement très pauvre qui appartient d'abord à ceux qui ne peuvent pasparler. 》

15 « Ni guerre de conquête, ni guerre de "défense nationale", la guerre d'Algérie est à peu près devenue une action propre à l'armée et à une caste qui refusent de céder devant un soulèvement dont même le pouvoir civil, se rendant compte de l'effondrement général des empires coloniaux, semble prêt à reconnaitre le sens. » 
Igualmente, se hizo una crítica a los civiles convertidos en policías como estrategia de Estado contra la población argelina oprimida que, en cambio, defendía una dignidad elemental: desear un país independiente. Por todo esto se reivindicaba el derecho a la insumisión y se alentaba a la deserción de los civiles para no participar en la guerra. La potencia de esta enunciación colectiva y anónima anuló, en términos de Foucault, la estrategia individualizadora de los gobiernos autoritarios y militaristas de amedrentar a los civiles. Al mismo tiempo, entre la calle y la escritura, se creó un espacio de solidaridad con los argelinos, en tanto hombres libres. No en vano, el "nosotros" es el modo de enunciación que caracteriza el manifiesto:

- Respetamos y consideramos justificado el rechazo de tomar las armas contra el pueblo argelino.

- Respetamos y consideramos justificada la conducta de los franceses que estiman que su deber es proporcionar ayuda y protección a los argelinos oprimidos en nombre del pueblo francés.

- La causa del pueblo argelino, que contribuye de manera decisiva a acabar el sistema colonial, es la causa de todos los hombres libres (Manifiesto de los 121, citado en Blanchot, 2008b, p. 53) ${ }^{16}$.

Emergieron entonces prácticas nuevas de resistencias que intentaron crear modos de vida en común allende nacionalismos y colonialismos. Sobre esta nueva resistencia, los 121 escribieron: "fuera de los marcos y las consignas preestablecidas, nació una resistencia gracias a una toma de conciencia espontánea, buscando e inventando formas de acción y medios de lucha ante una situación nueva" (Manifiesto de los 121, citado en Blanchot, 2008b, p. 52) ${ }^{17}$.

16 «-Nous respectons et jugeons justifié le refus de prendre les armes contre le peuple algérien. - Nous respectons et jugeons justifiée la conduite des Français qui estiment de leur devoir d'apporter aide et protection aux Algériens opprimés au nom du peuple français. - La cause du peuple algérien, qui contribue de façon décisive à ruiner le système colonial, est la cause de tous les hommes libres. »

17 « En dehors des cadres et des mots d'ordre préétablis, une résistance est née, par une prise de conscience spontanée, cherchant et inventant des formes d'action et des moyens de lutte en rapport avec une situation nouvelle. » 
Posteriormente, durante las movilizaciones de Mayo del 68, el Comité de Estudiantes y Escritores - entre los que se encontraban Marguerite Duras, Monique y Robert Antelme, Dionys Mascolo, Louis-René des Forêts, Michel Leiris, Maurice Nadeau, entre otros- crearon la Revista Internacional como un espacio de escritura colectiva y en solidaridad con aquellos que en diversos lugares del mundo tenían su libertad amenazada. Así, en un bello pasaje llamado $L a$ solidarité que nous affirmons ici... reiteraban el rechazo del sistema establecido y afirmaban la necesidad de otro mundo posible:

Insistimos en afirmar al mismo tiempo que, ante el sistema establecido, es de importancia capital, quizá decisiva, que el movimiento de los estudiantes, sin hacer promesas y, al contrario, rechazando cualquier afirmación prematura, oponga y mantenga una potencia de rechazo capaz, creemos, de abrir un futuro (citado en Blanchot, 2008b, p. 142) ${ }^{18}$.

Tras esta participación en las movilizaciones, Blanchot se distanció posteriormente de la izquierda francesa debido no solo al Gulag, sino a las posiciones proPalestina, país que, a su modo de ver, mantenía una postura antisemita. Blanchot escogió entonces una vida solitaria y anónima, en la que continuó sus actos y escritos políticos. Entre ellos quisiéramos destacar tres: 1) su apoyo al texto En vue de la défaite américaine. Appel international pour une rupture que fue publicado en 1967 por Antelme contra la Guerra de Vietnam; 2) Notre responsabilité contra el apartheid y en defensa de Mandela: "sepamos entonces que también nosotros somos responsables y culpables si no hacemos escuchar un llamado, una denuncia, un grito, un grito aún. Y seamos de aquellos que puedan repetir las palabras de Breyren Breytenbach dirigiéndose a Winnie Mandela: Nuestro corazón está contigo / África será liberada" (Blanchot, 2008b, p. 219) ${ }^{19}$; finalmente, 3) su texto dedicado a Antelme, Dans la nuit surveillée, este amigo incomparable,

18 «Nous tenons à affirmer en même temps que, face au système établi, il est d'une importance capitale, peut-être décisive, que le mouvement des étudiants, sans faire de promesses et, au contraire, en repoussant toute affirmation prématurée, oppose et maintienne une puissance de refus capable, croyons-nous, d'ouvrir un avenir. »

19 « Sachons donc que nous aussi nous sommes responsables et coupables, si nous ne faisons pas entendre un appel, une dénonciation, un cri et encore un cri. Et soyons tels que nous puissions répéter la parole de Breyren Breytenbach, s'adressant à Winnie Mandela : Notre cour est avec toi / L'Afrique sera libérée. » 
simple y que dejó un gran saber tras ser llevado a los campos de concentración: "él comprendió que en la vida misma hay un vacío, un vacío insondable del que hay que defenderse al tiempo que admitir su aproximación. Debemos aprender a vivir con este vacío. Nosotros mantendremos la plenitud hasta en la nada" (Blanchot, 2008b, p. 252) ${ }^{20}$. Al coraje de su resistencia escribe Blanchot: "Robert, aún me coloco junto a usted. Y esta 'noche de vigilia' en la que viene a verme no es una ilusión donde todo desaparecería; sino mi derecho a hacerle vivir hasta en el vacío cuya proximidad presiento" (Blanchot, 2008b, p. 252) ${ }^{21}$.

Paralelamente, Blanchot mantuvo una escucha y conversación continua en su vida y obra con escritores críticos de la época, con quienes no solo tuvo amistad, sino una solidaridad indeclinable, tales como Lévinas, Jabès, Bataille, Duras, Mascolo, Lévi, Char, Camus, entre otros ${ }^{22}$. Posteriormente, en su texto Los intelectuales en cuestión. Esbozo de una reflexión (2003), Blanchot sintetizaría varios argumentos básicos sobre su consideración de la figura del intelectual que inspiraron estas épocas. Parte entonces de una crítica a la figura clásica del intelectual ilustrado de ideales universalistas, debido a los desastres históricos que trajo la presunción de una razón válida para todos, con sus alcances racistas y colonialistas. A esto se suman los efectos nihilistas del pensamiento de la unidad y totalidad como sistema y sus respectivas ideas abstractas de hombre y justicia en general a que asistieron los hombres del siglo $\mathrm{xx}$ con las guerras mundiales. Simultáneamente, Blanchot se distancia de cualquier forma de irracionalismo, fascismo o totalitarismo y sus implicaciones en el nacionalismo genocida de la época, donde se destaca su crítica a la postura nacionalsocialista de Heidegger. El intelectual de Blanchot se distancia de ser un hombre de compromiso o portador de una conciencia universal, como en algunos momentos se tornó Sartre y, en cambio, "busca las razones de su insumisión, y tal vez de su renuncia, en sí

20 «Il comprit que dans la vie même il y a du néant, un vide insondable dont il faut se défendre, tout en admettant l'approche. Nous devons apprendre à vivre avec ce vide. Nous maintiendrons la plénitude jusque dans le néant. »

21 «Robert, j'ai encore ma place auprès de vous. Et cette "nuit surveillée" où vous venez me voir n'est pas une illusion où tout disparaitrait, mais mon droit à vous faire vivre jusque dans le néant dont je pressens l'approche. 》

22 L'amitié (1971) es justamente un libro dedicado a sus amigos, compañeros de vida y pensamientos. 
mismo" (Blanchot, 2003, p. 50), es un hombre más, duda, no aclama, asiente cuando hace falta, rechaza el fascismo como epidemia de un modelo universal, el antisemitismo, el racismo y la xenofobia. En lugar de un programa político, el intelectual tiene la responsabilidad de corresponder a una exigencia ética que lo aleja de la figura del líder y, en cambio, lo aproxima a la figura del centinela anónimo:

En la retaguardia de la política, no se aparta ni se interesa, sino que trata de mantener esa distancia y ese impulso de la retirada para aprovecharse de la proximidad que le aleja con el fin de instalarse en ella (precaria instalación), como un centinela que no estuviera allí más que para para vigilar, mantenerse despierto, escuchar con atención activa, que expresa menos la preocupación por sí mismo que la preocupación por los otros (Blanchot, 2003, p. 56).

Es en este sentido que Blanchot reconoce el llamado de Adorno a actuar de tal modo que Auschwitz no se repita, a la vez que señala su proximidad con Foucault contra las funciones del intelectual como conciencia de otros y con el rechazo al colonialismo de Char. Por todo esto, para Blanchot el intelectual es ante todo un hombre más, un anónimo con una exigencia ética clara: rechazar toda forma de universalismo, totalitarismo o fascismo genocida que niegue la posibilidad de existencia del otro y reduzca su alteridad. Por consiguiente, su tarea y búsqueda emerge y se desenvuelve en el anonimato y con los anónimos: "él solo es uno más entre muchos otros, con la esperanza (por vana que esta sea) de perderse en la oscuridad de todos y conseguir un anonimato que es incluso, en tanto escritor o artista, su aspiración más profunda siempre desmentida" (Blanchot, 2003, p. 113). En suma, este recorrido nos permite entrelazar a Foucault y Blanchot como intelectuales vigía o centinelas, pues, como observa Hoppenot (2008b) a propósito de los Écrits politiques (1953-1993) de Blanchot, estos corresponden a "una escritura vigilante, guardiana de lo más frágil, de lo excluido, de lo oprimido. La escritura política: responder a, responder por, exigente cuidado de la justicia" (p. 11) ${ }^{23}$.

23 «Une écriture vigilante, gardienne du plus fragile, de l'exclu, de l'opprimé. L'écriture politique: répondre à, répondre de, exigeant souci de justice. » 
En consecuencia, a continuación nos dedicaremos a la tercera arista desde la que podemos caracterizar al intelectual tal como lo concibe Blanchot por la responsabilidad de escribir aún ante las experiencias límite como el morir del otro. Esta responsabilidad del escritor se bosqueja en varias de las figuras del corpus literario de Blanchot, tales como: los testigos sin atestación o los últimos en hablar en Elpaso (no) más allá (1994); la singularidad provisional, la singularidad cualquiera o el último testigo en La escritura del desastre (1990). Con estas figuras se alude a una responsabilidad que excede al sujeto: "velar no es el poder de velar en primera persona, no es un poder, sino el alcance de lo infinito sin poder" (Blanchot, 1990, p. 47).

Ante la experiencia de la muerte del otro, el escritor mantiene la palabra para transgredir el límite de la muerte fáctica, al poner a reverberar su ausencia. Es por esto que el escritor no es más el sujeto que funda o centra el lenguaje, sino apenas una voz anónima que se dona a los anónimos, no para hablar "por" los ausentes ni para hablar "en lugar de" los ausentes, sino justamente para nombrar su ausencia e inaccesibilidad; de ahí que sea un habla "sin poder": "el Decir da y da respuesta, respondiendo a lo imposible y de lo imposible" (Blanchot, 1990, p. 24).

En este sentido, Blanchot retoma de Lévinas el concepto de alteridad con el que se problematiza la filosofía moderna, su reducción del pensamiento del otro a un alter ego, más aún, al poder de representación o reconocimiento del sujeto que tradicionalmente funda o proporciona el horizonte fenomenológico desde el que el otro aparece. Por consiguiente, el morir del otro no solo excede al escritor dislocando su voz de la primera a la tercera persona y tornándolo un anónimo entre anónimos, sino exponiéndolo a sus propios límites en cuanto sujeto:

En la relación de mí (el mismo) con el Otro, el Otro es el lejano, lo ajeno, mas si invierto la relación, el Otro se relaciona conmigo como si yo fuese Lo Otro y entonces me hace salir de mi identidad, apretándome hasta el aplastamiento, retirándome bajo la presión de lo muy cercano, del privilegio de ser en primera persona y, sacado de mí mismo, dejando una pasividad privada de sí (alteridad misma, otredad sin unidad) (Blanchot, 1990, p. 23).

Por todo esto, el escritor apenas responde al morir del otro con su vela y cuidado en medio de la escritura: "siempre alerta, hasta el punto de que no parecía quedar de él más que el vacío de una vigilancia, la ausencia” (Blanchot, 1994, p. 53). 
Y, no obstante, esta es la exigencia a la que hay que responder: "Velar por el sentido ausente" (Blanchot, 1990, p. 42). En contraste con cualquier forma de patetismo, emerge aquí una literatura testimonial o, si se quiere, una poética espectral de los que retornan (revenant) del desastre para nombrar los ausentes ${ }^{24}$. En términos de Hoppenot (2014):

La escritura del desastre pone en escena una verdadera poética que privilegia el fragmento, como ya lo anunciaba Primo Lévi en sus palabras de introducción de Si esto es un hombre. El fragmento imita la fractura, las ruinas, los trozos, escapa a toda voluntad cronológica, a cualquier reagrupamiento, dice lo inconmensurable de la pérdida y su repetición. Deconstruye la posibilidad incluso de la narración [...] Da a la desaparición, a la ceniza, una voz a la vez anónima y singular, tal podría ser entonces la tarea de la escritura del desastre (p. 202).25

En suma, el intelectual o escritor que se caracteriza aquí es un velador de los ausentes: "abrazados, separados: testigos sin atestación, que venian hacia nosotros, que venian también el uno hacia el otro" (Blanchot, 1994, p. 115). Su responsabilidad persiste y resiste en una escritura que nombra la ausencia sin apropiarla: "una mano que se tiende, que se niega, que, de todas maneras, nopodriamos asir” (p. 137). El ejercicio ético de la escritura se juega, por tanto, en esta hospitalidad de una voz anónima que acoge en el espacio narrativo las voces anónimas de los ausentes, o si se quiere, que se dona a esta "amistad para con el desconocido sin amigos" (p. 167).

\section{Consideración final}

TRAS ESTE RECORRIDO por las inquietudes de Foucault y Blanchot en torno al lenguaje, las relaciones de poder y la ética, podemos caracterizar la figura del

24 Considérense, por ejemplo, las obras literarías de Celan, Delbo, des Forêts, Caproni, Montale, Char, entre otros.

25 «L'écriture du désastre met en scène une véritable poétique, qui privilégie le fragment, comme l'annonçait déjà Primo Levi dans ses quelques mots d'introduction à Si c'est un homme. Le fragment mime le bris, le débris, l'éclat, il échappe à toute volonté chronologique, à tout rassemblement, il dit l'incommensurable de la perte et son ressassement. Il déconstruit la possibilité même de toute narration [...]. Donner à toute disparition, à toute cendre, une voix tout à la fois anonyme et singulière, telle pourrait donc être la tâche de l'écriture du désastre. » 
intelectual, en primer lugar, como una voz anónima entre voces anónimas, que se expone a las experiencias límite para interpelar el pensamiento, allí donde es necesario problematizar sus discursos, su voluntad de verdad o, como en la literatura, afirmar el pasaje de la primera a la tercera persona para prestar oídos y componer comunidad literaria con otros anónimos. En segundo lugar, el intelectual se asume como un vigía o velador, que bien nos describe Foucault al decir: "esta vela se cruza con otras vigilancias: la de los buenos acechadores cuya espera multiplicada traza en la sombra el dibujo todavía sin figura del día que llega" (Foucault, 1999a, p. 199). Este vigía o velador no es guía, no habla "en lugar de" otros ni "por" otros; es más bien un punto de vista cualquiera, una escucha atenta y aguzada. En tercer lugar, el intelectual corresponde a una exigencia ética, en el caso de Foucault, a un ejercicio y experimentación continuos de prácticas o modos de vida menos gobernados, a un cuidado de la libertad de sí y del otro. Paralelamente, en Blanchot el intelectual asume la exigencia ética de escribir para acoger a los ausentes, a los desaparecidos, esto es, de componer una comunidad literaria con los anónimos. En suma, la tarea el intelectual desde Foucault y Blanchot converge en esta solidaridad con los anónimos, esta que parte desde nuestras vidas cotidianas, se juega en los anónimos que nos tornamos nosotros mismos ante las experiencias inesperadas, acontece en nuestra relación con los otros próximos o extraños y, en fin, nos interpela cada vez en la escritura.

Referencias

Adorno, F. P. (2010). La tarea del intelectual: el modelo socrático. En: F. Gros. (Ed.), Foucault. El coraje de la verdad (pp. 33-52). (Trad. A. Sánchez). Madrid: Arena Libros.

Antonioli, M. (2012). Ecos de lo común. Instantes y Azares. Escrituras Nietzscheanas, 11, 201-217.

Artières, P. (2010). Decir la actualidad. El trabajo de diagnóstico en Michel Foucault. En: F. Gros. (Ed.), Foucault. El coraje de la verdad (pp. 13-32). (Trad. A. Sánchez). Madrid: Arena Libros.

Benveniste, E. (1997, 1999). Problemas de lingüistica general (Vols. 1-2). Ciudad de México: Siglo XXI.

Blanchot, M. (1986). Foucault tel que je l'imagine. París: Éditions Fata Morgana. 
Blanchot, M. (1990). La escritura del desastre. (Trad. P. de Place). Caracas: Monte Ávila Editores.

Blanchot, M. (1993). De Kafka a Kafka. (Trad. J. Ferreiro). Buenos Aires: Fondo de Cultura Económica.

Blanchot, M. (1994). Elpaso (no) más allá. (Trad. C. Peretti). Barcelona: Paidós. Blanchot, M. (2002). El espacio literario. (Trad. V. Palant \& J. Jinkis). Madrid: Editora Nacional.

Blanchot, M. (2003). Los intelectuales en cuestión. Esbozo de una reflexión. (Tr. M. Arranz). Madrid: Tecnos.

Blanchot, M. (2008a). La conversación infinita. (Trad. I. Herrera). Madrid: Arena Libros.

Blanchot, M. (2008b). Maurice Blanchot : Écrits politiques 1953-1993. E. Hoppenot (Ed.). París: Gallimard.

Bordeleau, E. (2012). Foucault anonymat. Québec: Le Quartanier.

Castro, S. (2015). Historia de la gubernamentalidad. Razón de Estado, liberalismo y neoliberalismo en Michel Foucault. Bogotá: Siglo del Hombre.

Foucault, M. (1968). Las palabras y las cosas. Una arqueología de las ciencias humanas. (Trad. E. C. Frost). Buenos Aires: Siglo XXI.

Foucault, M. (1979). La arqueología del saber. (Trad. A. Garzón). Ciudad de México: Siglo XXI.

Foucault, M. (1990). Omnes etsingulatim. Hacia una crítica dela "razón política. (Trad. M. Allendesalazar). Tecnologías del yo (pp. 95-140). Barcelona: Paidós.

Foucault, M. (1991). El sujeto y el poder. (Trad. E. Garavito). Bogotá: Ediciones Carpe Diem.

Foucault, M. (1992). El orden del discurso. (Trad. A. González Troyano). Buenos Aires: Tusquets.

Foucault, M. (1997). El pensamiento del afuera. (Trad. M. Arranz Lázaro). Valencia: Pre-Textos.

Foucault, M. (1999a). Entre filosofía y literatura. (Trad. M. Morey). Barcelona: Paidós.

Foucault, M. (1999b). Estrategias de poder. (Trad. J. Varela y F. Álvarez). Barcelona: Paidós. 
Foucault, M. (1999c). Estética, ética y hermenéutica. (Trad. Á. Gabilondo). Barcelona: Paidós.

Foucault, M. (2000). Defender la sociedad. (Trad. H. Pons). Buenos Aires: Fondo de Cultura Económica.

Foucault, M. (2005).¿Quées un autor? Recuperado de: http://23118.psi.uba.ar/ academica/carrerasdegrado/musicoterapia/informacion_adicional/311_escuelas_psicologicas/docs/Foucault_Que_autor.pdf

Foucault, M. (2006). Seguridad, territorio, población. (Trad. H. Pons). Buenos Aires: FCE.

Foucault, M. (2013). La inquietud por la verdad. Escritos sobre la sexualidad y el sujeto. (Trad. H. Pons). Buenos Aires: Siglo XXI.

Gros, F. (2003). À propos de l'hermenéutique du sujet. En: Foucault au Collège de France: un itinéraire (pp. 149-163). Bordeaux: Presses Universitaires de Bordeaux.

Hoppenot, E. (2008). Avertissement. En: M. Blanchot. Maurice Blanchot : Écrits politiques 1953-1993 (pp. 7-11). E. Hoppenot (Ed.). París: Gallimard.

Hoppenot, E. (2014). L'écriture du désastre. Témoigner. Entre histoire et mémoire, 118, 202. doi: 10.4000/temoigner.1263

Martínez, R. (2011). Maurice Blanchot: La exigencia politica (Tesis doctoral). Zaragoza: Prensas de la Universidad de Zaragoza.

Morey, M. (2014). Escritos sobre Foucault. Madrid: Editorial Sexto Piso.

Quintana, I. (2014). La exigencia de un habla plural. Literatura, pensamiento y comunidad en la obra de Maurice Blanchot (Tesis doctoral inédita). Recuperado de: Dialnet (código de acceso 98393).

Quintana, I. (2018). Práctica del intelectual más allá del saber: Lyotard, Foucault, Blanchot. Isegoria, 59, 425-446. doi: 10.3989/isegoria.2018.059.04

Revel, J. (2005a). Subjectivité et processus de subjectivation. En: Michel Foucault. Expériences de la pensée (pp. 169-205). París: Editorial Bordas.

Revel, J. (2005b). L'invention de soi. En: Michel Foucault. Expériences de la pensée (pp. 207-214). París: Editorial Bordas. 